\title{
Molecular Cloning of a Novel Membrane Glycoprotein, Pal, Specifically Expressed in Photoreceptor Cells of the Retina and Containing Leucine-Rich Repeat
}

\author{
Fumi Gomi, 1,2,4 Kazunori Imaizumi, 1,3,4 Takunari Yoneda, ${ }^{1,4}$ Manabu Taniguchi, ${ }^{1,4}$ Yasutake Mori, 1,4 \\ Ko Miyoshi,, 1,4 Junichi Hitomi,, ${ }^{1,4}$ Takashi Fujikado,2 Yasuo Tano, ${ }^{2}$ and Masaya Tohyama ${ }^{1,4}$ \\ Departments of ${ }^{1}$ Anatomy and Neuroscience and ${ }^{2}$ Ophthalmology, Graduate School of Medicine, Osaka University, Suita, \\ Osaka 565-0871, Japan, ${ }^{3} T a n a b e ~ S e i y a k u ~ C o m p a n y ~ L i m i t e d, ~ Y o d o g a w a k u, ~ O s a k a ~ 532-0031, ~ J a p a n, ~ a n d ~{ }^{4}$ Core \\ Research for Evolutional Science and Technology, Japan Science and Technology Corporation, Kawaguchi, \\ Saitama 332-0012, Japan
}

\begin{abstract}
We have isolated a novel retina-specific gene in a screen for genes of which expression is not apparent neonatally in rat retina but is abundant postnatally on day 14 (P14). This gene, named $\mathrm{Pal}$, encodes a putative type I transmembrane protein containing five leucine-rich repeats (LRRs), a single C2-type Ig-like domain, and a single fibronectin type III domain and is considered to be a new member of the LRR and Ig superfamily. No expression of $\mathrm{Pal}$ was found in rat retina at $\mathrm{P} 1$, but it was detected at P7 and markedly increased with subsequent development. These expression patterns of $\mathrm{Pal}$ appeared to be correlated with the development of the photoreceptor outer
\end{abstract}

The development of the neural retina goes through steps of neuronal specification and differentiation. In the rodent retina, the majority of ganglion cells, cones, and horizontal cells develop before birth, whereas most rods develop after birth (for review, see Reh, 1992; Cepko et al., 1996). Around postnatal day 7 (P7), the outer nuclear layer and the inner nuclear layer are separated by the outer plexiform layer, and the rod outer segments in which phototransduction is carried out begin to appear. At approximately the same time, the levels of expression of photoreceptorspecific genes such as rhodopsin (Hicks and Barnstable, 1987), cGMP-gated ion channel (Ahmad et al., 1990), and arrestin (Ni et al., 1992) increase rapidly. On P9 a small a-wave can first be detected physiologically by electroretinogram (ERG), and $2 \mathrm{~d}$ later a positive b-wave also appears (Grun, 1982). Just before the ERG can be recorded, avoidance behavior is noted as the first reaction to light (Grun, 1982). Thus, significant changes occur in the retina leading to both morphological and functional maturation in the first $10 \mathrm{~d}$ after birth, and the genes that begin to be expressed in the retina at this stage could play crucial roles in the specialized functions of the retina.

Isolations of retina-specific genes have been attempted over the last decade. Such genes include rhodopsin (Nathans and Hogness, 1984), transducin (Lochrie et al., 1985), and cGMP-gated channel (Cook et al., 1987; Körschen et al., 1995), which are involved in phototransduction, and peripherin/rds (Connell and Molday, 1990) and rom-1 (Bascom et al., 1992), which are involved in

\footnotetext{
Received Sept. 7, 1999; revised Feb. 11, 2000; accepted Feb. 18, 2000.

Correspondence should be addressed to Dr. Fumi Gomi, Department of Anatomy and Neuroscience, Graduate School of Medicine, Osaka University, 2-2 Yamadaoka, Suita, Osaka 565-0871, Japan. E-mail: fgomi@anat2.med.osaka-u.ac.jp.

Copyright (c) 2000 Society for Neuroscience 0270-6474/00/203206-08\$15.00/0
}

segments, because in the adult rat retina it was specifically localized in these segments. Ultrastructually, Pal immunoreactivity was distributed diffusely on the disk membrane in the lamellar regions. On the basis of its structural features and localization pattern, Pal may act as a receptor for a certain trophic factor or for an adhesion molecule participating in morphogenesis. The human homolog of Pal was mapped to chromosome 10q23.2-23.3 using fluorescence in situ hybridization.

Key words: retina; Pal; leucine-rich repeat; immunoglobulin superfamily; fibronectin III; photoreceptor outer segment morphogenesis of the retina. Among these, causative genes for inherited diseases of the retina have been identified by positional cloning or candidate gene approaches. For example, mutations in rhodopsin or peripherin/rds contribute to autosomal dominant retinitis pigmentosa (RP) (Dryja et al., 1990; Kajiwara et al., 1991). Thus, isolating genes uniquely expressed in the retina could lead to the clarification of the molecular mechanisms of phototransduction or the development of retinal disorders.

In the present study, we screened for genes the transcripts of which were not apparent at P1, but were clearly apparent at P14 when development of the retina is morphologically and functionally complete. We isolated several cDNA fragments using the differential display technique. One of these was a novel gene encoding a membrane glycoprotein containing a leucine-rich repeat (LRR), a C2-type Ig-like domain, and a fibronectin (FN) type III domain, and the transcript of which was specifically expressed in the retina. This novel retina-specific protein was considered to be a new member of the LRR and Ig superfamily and was named Pal (photoreceptor-associated LRR superfamily). We report here the structural properties and the expression patterns of this gene in the retina, plus we discuss its potential function.

\section{MATERIALS AND METHODS}

Differential display. Total RNA was isolated from P1 and P14 rat retina, and the differential display was performed as described previously (Imaizumi et al., 1994). Briefly, total RNA (3 $\mu \mathrm{g}$ ) was converted to cDNA with Moloney murine leukemia virus reverse transcriptase (Life Technologies, Rockville, MD). Subsequently, each pool of cDNA was amplified by PCR with 200 different arbitrary primers. After separation by $5 \%$ PAGE, cDNA bands that were amplified abundantly only from the cDNA derived from the P14 retina were recovered from the gel, ream- 
plified with the corresponding primer, and cloned into the pGEM-T vector (Promega, Madison, WI).

cDNA library screening. A rat retina cDNA library constructed in the Uni-ZAP XR vector (Stratagene, La Jolla, CA) was screened using the cDNA fragment obtained from the differential display as a probe by the standard methods. To obtain the sequence of human homolog of Pal, a human retina cDNA library (Clontech, Palo Alto, CA) was screened using the rat cDNA probe containing a full-length Pal coding region.

$D N A$ sequencing and analysis. Sequencing was performed by the dideoxy chain-termination method, using the Taq dye primer cycle sequencing kit (Perkin-Elmer, Norwalk, CT) and the 373A DNA sequencer (Applied Biosystems, Foster City, CA). The final sequence was confirmed from both strands. Homology searches were performed using the FASTA and BLAST programs in any available DNA or protein data bases. Possible protein motifs in the conceptual amino acids sequence were determined using the MOTIFS program with the PROSITE dictionary.

Northern blot analysis. Total RNA was extracted from developing (P1, P7, and P14) and adult (P56) rat retina and P56 rat organs. Ten micrograms of each total RNA were fractionated by electrophoresis through $1.0 \%$ agarose/formaldehyde gel and transferred onto Immobilon- $\mathrm{N}$ membrane (Millipore, Bedford, MA). The membrane was hybridized with ${ }^{32} \mathrm{P}$-labeled Pal probe. After washing in $2 \times \mathrm{SSC}, 0.1 \%$ SDS and $0.1 \times$ SSC, $0.1 \%$ SDS, the membrane was dried and autoradiographed.

In situ hybridization. Frozen sections $(12 \mu \mathrm{m}$ thick) of the rat retina (P1, P7, P14, and P56) were made and thaw-mounted onto poly-L-lysinecoated slides. Digoxygenin-labeled cRNA probes (antisense and sense) were prepared by in vitro transcription using T7 and T3 RNA polymerase from partial Pal cDNA subcloned into pBluescript SK $(-)$ (Stratagene) in the presence of digoxygenin-labeled d-UTP (Boehringer Mannheim, Mannheim, Germany). Hybridization and posthybridization procedures were performed as described previously (Imaizumi et al., 1994).

Generation of anti-Pal polyclonal antibodies. To obtain polyclonal antibody against Pal, a peptide with the sequence SREPSEHQETQMVRSL (amino acids 419-434) (see Fig. 1) was synthesized and conjugated to keyhole limpet hemocyane. Two rabbits were immunized by conventional methods, and antisera was obtained. The antibody was purified by affinity chromatography using a ProtOn kit1 (Multiple Peptide Systems, San Diego, CA) column with immobilized Pal-derived synthetic peptide.

Preparation of membrane fractions from rat retina and immunoblotting. Frozen rat retinas were homogenized in PBS and centrifuged at $18,000 \times g$ for $10 \mathrm{~min}$. The pellets were solubilized and incubated in 10 mM Tris-acetate, $\mathrm{pH} 8.0,1 \mathrm{~mm}$ EDTA, and $0.5 \%$ Nonidet $\mathrm{P}-40$ for $90 \mathrm{~min}$ at $4^{\circ} \mathrm{C}$. The supernatants were collected after a $90 \mathrm{~min}$ spin at $40,000 \times$ $g$. The membrane protein from rat brain was collected in the same manner as a control.

Transient transfection of Pal cDNA in mammalian cells. To generate Pal expression plasmids, FLAG or hemagglutinin (HA) epitope sequence was attached to the $\mathrm{C}$ terminus of $\mathrm{Pal}$ and cloned into pCDNA3.1 $(+)$ (Invitrogen, Carlsbad, CA). HeLa cells on $6 \mathrm{~cm}$ dishes were transiently transfected with $8 \mu \mathrm{g}$ of expression plasmid DNA of Pal tagged with the FLAG by lipofection with lipofectAMINE 2000 (Life Technologies) for immunofluorescence experiments.

Human embryonic kidney 293T cells on $10 \mathrm{~cm}$ dishes were transfected with $10 \mu \mathrm{g}$ of plasmid DNA of FLAG-tagged or HA-tagged Pal, or both by lipofection with lipofectAMINE (Life Technologies). Cells were grown to near confluence, harvested, and lysed in $1 \mathrm{ml}$ of buffer containing $10 \mathrm{~mm}$ Tris-HCl, pH 7.8, 0.2\% Nonidet P-40, $0.15 \mathrm{M} \mathrm{NaCl}, 1 \mathrm{~mm}$ EDTA, and $5 \mu \mathrm{g} / \mathrm{ml}$ aprotinin (lysis buffer) for immunoprecipitation or Western blotting.

Immunoprecipitation and immunoblotting. Membrane protein fraction from the retina and the brain was incubated for $2-4 \mathrm{hr}$ at $4^{\circ} \mathrm{C}$ with $20 \mu \mathrm{l}$ of anti-Pal polyclonal antibody. Recombinant protein-G agarose (Life Technologies) was added to each sample followed by a further $2-4 \mathrm{hr}$ incubation at $4^{\circ} \mathrm{C}$. The beads were then washed five times. After the last wash, all buffer was removed, and reducing sample buffer was added to each reaction mixture. Samples were boiled and loaded onto 5-20\% gradient SDS-PAGE. After electrophoresis, gels were electrotransferred to Immobilon $\mathrm{P}$ (Millipore). The blots were incubated with anti-Pal polyclonal antibody diluted to $1: 50$ in PBS with $0.1 \%$ Tween-20 (PBST) after blocking with 5\% nonfat milk. Detection was performed with $0.1 \%$ alkaline phosphatase-conjugated goat anti-rabbit IgG (Boehringer Mannheim).

For immunoprecipitation experiments, 293T cell lysates were centri- fuged at $12,000 \mathrm{rpm}$ for $5 \mathrm{~min}$ to remove large cellular debris. The supernatants were incubated with $3 \mu \mathrm{l}$ of anti-FLAG epitope monoclonal antibody (Sigma, St.Louis, MO) or $1 \mu$ l of anti-HA epitope polyclonal antibody (Berkeley Antibody Company, Richmond, CA), and immunoprecipitation assays were performed as described above. Samples were applied to SDS-PAGE, and the gels were electrotransferred to the membranes. The samples immunoprecipitated by anti-FLAG antibody were incubated with anti-HA epitope polyclonal antibody (Berkeley Antibody Company) diluted to 1:500, and those immunoprecipitated by anti-HA antibody were incubated with anti-FLAG monoclonal antibody (Sigma) diluted to 1:1000 in PBST. Detection was performed with $0.1 \%$ alkaline phosphatase-conjugated goat anti-mouse IgG (Sigma) or antirabbit IgG (Boehringer Mannheim).

Immunofluorescence microscopy and electron microscopy. To confirm the subcellular localization of Pal, double staining of Pal and GRP78 was performed. GRP78 is a molecular chaperone in the endoplasmic reticulum (ER) lumen and is used as the ER marker. HeLa cells transfected with FLAG-tagged Pal were fixed with Zamboni solution. After fixation, the cells were washed with $0.02 \mathrm{M}$ PBS. Primary antibodies were applied for $2 \mathrm{hr}$ at room temperature in $0.1 \mathrm{M}$ PBS containing 3\% BSA with $0.2 \%$ saponin or $0.3 \%$ Triton X-100, or without any permeabilizing detergent. Dilution factors were $100 \times$ for anti-Pal polyclonal antibody, $500 \times$ for anti-FLAG monoclonal antibody (Sigma), and $500 \times$ for anti-GRP78 monoclonal antibody (StressGen Biotechnologies, Victoria, British Columbia, Canada). After washing in $0.02 \mathrm{M}$ PBS, the sections were incubated for $2 \mathrm{hr}$ with FITC-labeled goat anti-rabbit IgG (Jackson ImmunoResearch Laboratories, West Grove, PA) or Alexa 546-labeled goat anti-mouse IgG (Molecular Probes, Eugene, OR) for immunofluorescent labeling.

For immunohistochemistry of retina, the eye cups made from P0, P7, P14, and P56 rat were fixed with Zamboni solution by overnight immersion at $4^{\circ} \mathrm{C}$, soaked in $30 \%$ sucrose/PBS for $4 \mathrm{hr}$, and then frozen. Retinas were sliced into $12 \mu \mathrm{m}$ sections and adhered to poly-L-lysine-coated slides. Sections were washed in $0.02 \mathrm{M}$ PBS and incubated overnight at $4^{\circ} \mathrm{C}$ using a 1:100 dilution of polyclonal antibody against Pal in $0.1 \mathrm{M}$ PBS containing $3 \% \mathrm{BSA}$ and $0.3 \%$ Triton $\mathrm{X}-100$. After washing in $0.02 \mathrm{M}$ PBS, the sections were incubated for $2 \mathrm{hr}$ with adequate secondary antibody, biotinylated anti-rabbit IgG solution from $\mathrm{ABC}$ kit (Vector Laboratories, Burlingame, CA) for diaminobenzidine (DAB) staining or FITCconjugated goat anti-rabbit IgG (Jackson ImmunoResearch Laboratories) for immunofluorescent labeling. In slides for DAB staining, color was developed by incubation with $0.1 \mathrm{M}$ Tris-HCl buffer, $\mathrm{pH} 7.6$, containing $0.03 \%$ DAB and $0.01 \%$ hydrogen peroxide. In control studies, retinal sections were absorbed with excess $(100 \mu \mathrm{M})$ of synthesized peptide in diluted anti-Pal antibodies.

For electron microscopy, glutaraldehyde-fixed, London Resin (LR) White (London Resin; Berkshire, UK) resin-embedded rat retina sections were labeled with the polyclonal antibody for Pal overnight and subsequently treated with gold-labeled anti-rabbit IgG (British Biocell, Cardiff, UK).

Chromosomal localization by fluorescence in situ hybridization. The human genome BAC library was screened commercially (Genome Systems, St. Louis, MO) with $1.3 \mathrm{~kb}$ human Pal cDNA probe. The BAC DNA was purified from the positive clone and confirmed its sequence. The purified DNA was labeled with digoxigenin d-UTP by nick translation. Labeled probe was combined with sheared human DNA and hybridized to normal metaphase chromosomes derived from PHAstimulated peripheral blood lymphocytes in a solution containing $50 \%$ formamide, $10 \%$ dextran sulfate, and $2 \times$ SSC. Specific hybridization signals were detected by incubating the hybridized slides in fluoresceinated anti-digoxigenin antibodies followed by counterstaining with DAPI.

\section{RESULTS}

\section{Isolation and sequence analysis of Pal cDNA}

After screening by differential display, 12 cDNA fragments were found to be markedly amplified in the P14 rat retina. Some of these were known photoreceptor-specific genes, including rhodopsin, G-protein $\alpha$ subunit, and interphotoreceptor matrix proteoglycan (IMPG)-1. In addition, three novel genes were identified. In the present study, one of these novel genes, which we named Pal, was selected for further analysis.

The size of the initial cDNA fragment of Pal subcloned into the pGEM-T vector was 293 bp. This clone was used to screen a rat 
A

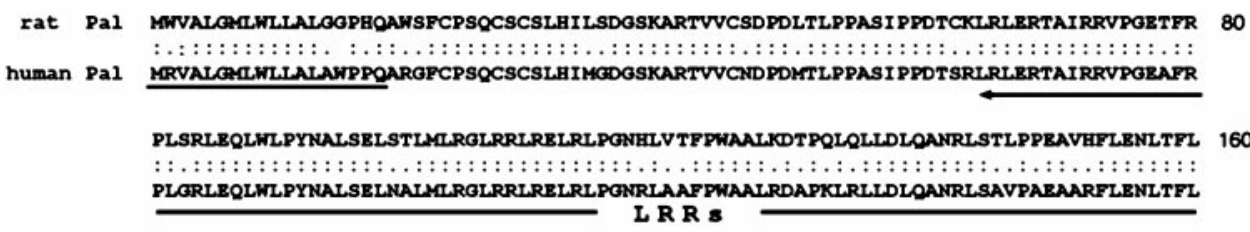

DLSNNQLMRLPEELLDTWAHLKTGPYLSSRRTRLVLOLODNPWVCDCRLYDLVHLLDGWASNLIFI EARLRCGSPRSLAO 240

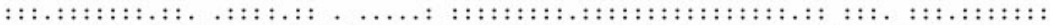
DLSSNQLHRLPQELIVSWAHLETOIFPPGHHPRRVLOLODN PWACDCRLYDLVHLLDGWAPNLAFIETELRCASPRSLAO

VAFSQLELRKCQSPELRPGVTSI I SPLOSTVLLRCGATGI PGPEMSWRRANGRPLNGTVHQEVSSDGSSWTLLDLPVVSL 320

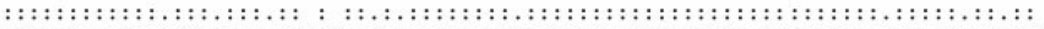
VAFSQLELRKCQGPELHPGVASIRSLLGGTALLRCGATGVPGPEMSWRRANGRPLNGTVBQEVSSDGTSWTLLGLPAVSH I g C 2

FDSGDY ICQAKNFLGASETLI SLIVTEPQTSTEYTGI PGALWARTGBGARAAAYNNKLVARHVPHVPEPVALATKPSVPS 400

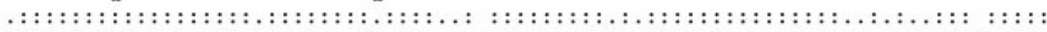
LDSGDY I COAKNFLOASETVISLIVTEPPTSTEBSGSPGALWARTGGGGEAAAYNNKLVARHVPQI PKPAVLATGPSVPS 

IKEELPLQNFOMDVPGEFSREPSEHQETOMVRSKVVGDTYHSVSLVWKAPQAONTTAFSVLYAVFOQRDMRRMTVEAGK 480

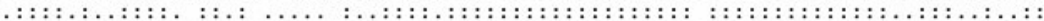
TKBELTLBHFQMDALOBLSDGRAOPSBARYVRSVKVVGDTYBSVSLVWKAPOAKNTTAFSVLYAVFGQHSPRRVIVQPGK $\longleftarrow$ FN III

TSVTIBGLAPKTKYVACVCVRGLVPTKBOCVIFSTDEVVDA BGTQRLINMVVISVAAI IALPPT Y VCCGALRRCHKCR 560

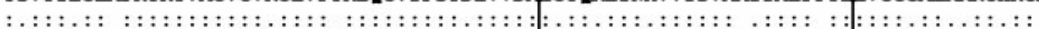
TRVT I TOLLPKTKYVACVCVQGLVPRKEQCVIF STNEVVDA SNTQQLINVVVI SVAIVIALPLTILVCCSALOKRCPKCF

AGGSAEASGAYVNLERLGHSEDGSELSRSSLSEADRLLSARSSLDSQVLOVRGGRINEYFC 623

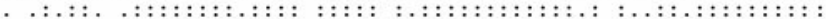
NIKDSTRATVTYVNLRRLOY SRDGLERLSRHSVSRADRLLSARSSVDFOAFGVKGGRRINEYFC

B

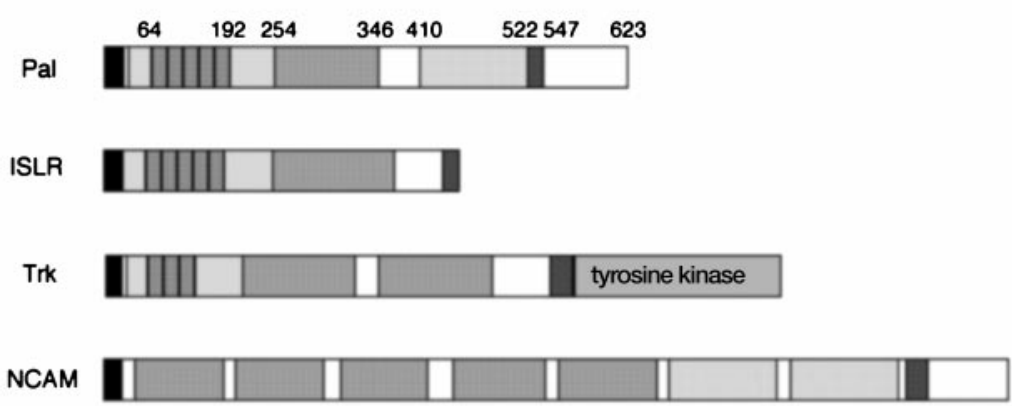

Figure 1. Primary structural properties of Pal. $A$, The deduced amino acid sequences of rat and human Pal. Numbering of amino acid residues is indicated in the right column. The putative signal peptide is underlined, and the transmembrane region is boxed. Identical amino acids are indicated by $c o$ lons, and conservative changes are shown as periods. The LRRs, Ig C2, and FN III domains are indicated with arrows underneath the included sequences. $B$, Schematic diagrams showing the structural features of Pal, ISLR, Trk, and NCAM.

signal peptide

$\lg \mathrm{C} 2$

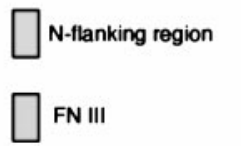

LRR

transmembrane retina cDNA library. The largest cDNA insert obtained was 4.1 $\mathrm{kb}$, which was consistent with the size of the Pal transcripts detected by Northern blot analysis ( $4.3 \mathrm{~kb}$; see Fig. 2).

Sequence analysis showed that this cDNA was a novel gene and had an open reading frame of 1869 bp encoding a putative protein of 623 amino acid residues (Fig. 1 $A$ ). Its hydropathy profile revealed that $\mathrm{Pal}$ had two hydrophobic segments. The amino terminus segment was considered to serve as a signal sequence, and another hydrophobic region (amino acids 522-547) represented a transmembrane domain. Comparative protein database analysis showed that it has three distinct motifs in the putative extracellular region: LRR, Ig C2-like domain, and FN III-like domain (Fig. 1B).

Toward the amino end, Pal contained five contiguous LRRs (amino acids 64-192) characterized by the specific spacing of leucine and asparagine residues. The last repeat contained nine more amino acid residues than the common 24-residue repeat. These repeats were flanked by a cysteine-rich amino-flanking consensus region (amino acids 24-63) and a carboxy-flanking region (amino acids 193-253). One C2-type Ig-like domain (amino acids 254-346) was identified following the carboxy-flanking region. It had two cysteine residues for a putative disulfide bond at the canonical position, which is characteristic of the $\mathrm{C} 2$ subcategory. There was also one FN III domain (amino acids 410521) following the Ig-like motif. In the intramembrane region, however, no recognizable structural features such as kinase domains were detected.

This overall structure containing these three motifs is considered to represent a new class of putative transmembrane protein, although combinations of two of the three motifs in transmem- 
A

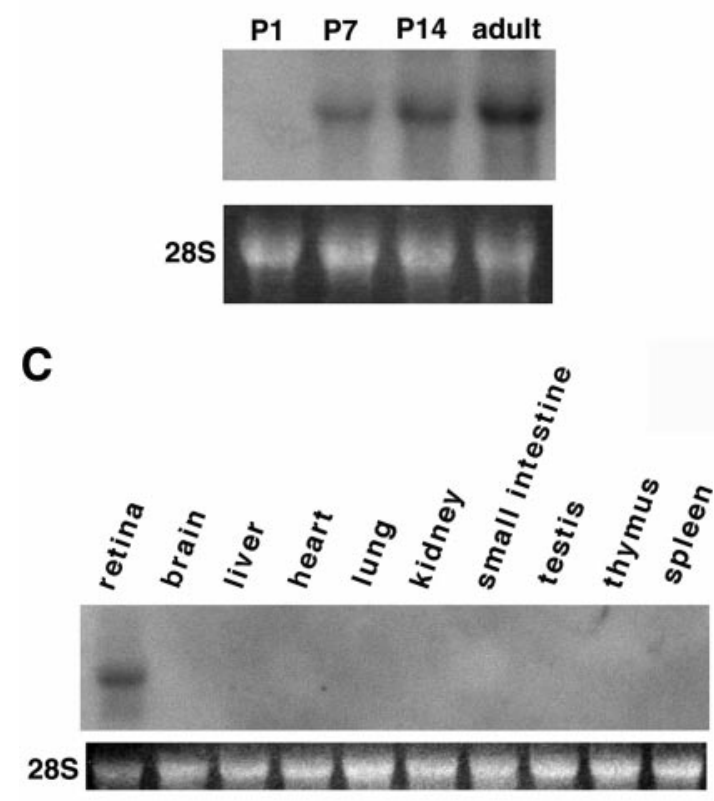

B
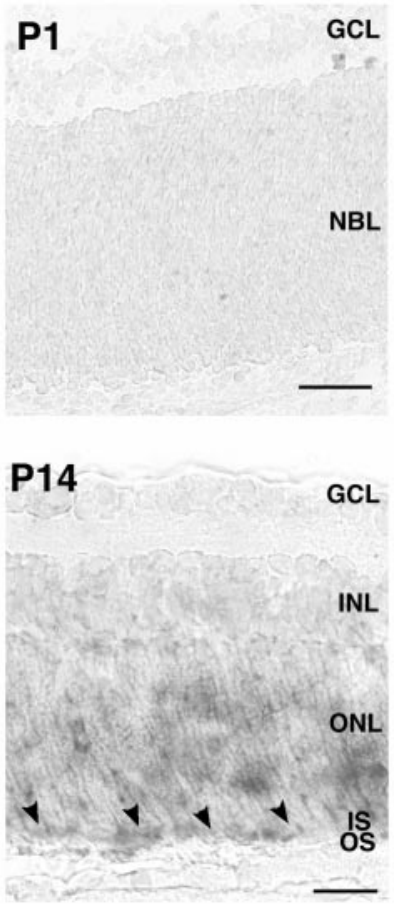
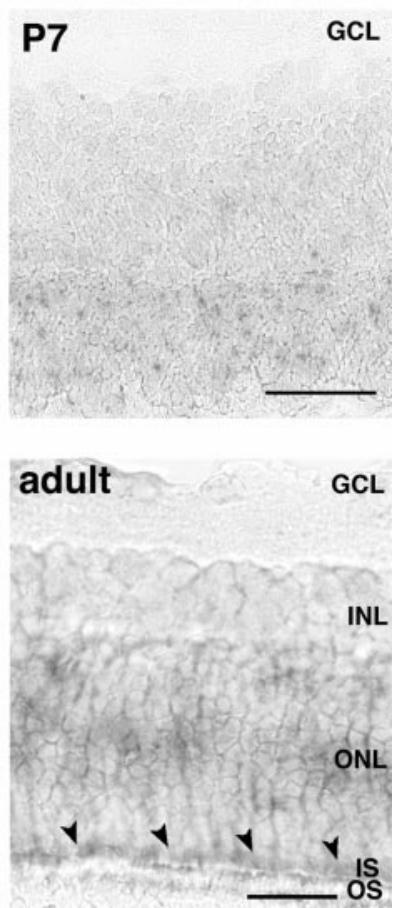

Figure 2. Expression of Pal mRNA in each developmental stage of the rat retina and tissue distribution. $A$, Northern blotting of Pal mRNA in the rat retina; $10 \mu \mathrm{g}$ of total RNA was isolated on the specified day. P1, Postnatal day $1 ; P 7$, postnatal day 7; P14, postnatal day $14 ;$ adult, postnatal day 56. Ethidium bromide-stained rRNAs $(28 S)$ indicate that the amounts of total RNAs were nearly equivalent in each lane. $B$, In situ hybridization of the rat retina with Pal cRNA probe. No signals were detected at P1. Weak signals of Pal mRNA were observed in the presumptive photoreceptor layer at P7. The P14 and adult retina showed intense expression of Pal mRNA in the outer nuclear layer and inner segment. Arrowheads indicate the signals of Pal mRNA at the inner segment. $G C L$, Ganglion cell layer; $N B L$, neuroblastic layer; $I N L$, inner nuclear layer; $O N L$, outer nuclear layer; $I S$, inner segment; $O S$, outer segment. Scale bar, $50 \mu \mathrm{m}$. $C$, Northern blot analysis of Pal mRNA in various tissues from adult rat. The top panel shows a single hybridization signal obtained with a rat Pal cDNA probe. The bottom panel shows ethidium bromide-stained rRNA (28S). Each lane contained $10 \mu \mathrm{g}$ of total RNA. The size of the expressed transcript was $\sim 4.3 \mathrm{~kb}$, and the signal was seen only in the retina.

brane proteins have been identified as Trk (Schneider and Schweiger, 1991) or NCAM (Small et al., 1987) (Fig. 1B). A homology search showed the closest relationship to ISLR, which is a recently cloned putative membrane protein in the human retina containing both the LRR and Ig-like motif (Nagasawa et al., 1997).

The human homolog of Pal cDNA also contained an open reading frame of 623 amino acids. Comparison of the human and rat deduced protein sequences showed that they were highly homologous, with an overall homology of $78.8 \%$. The functional domains found in the rat Pal sequence were also contained in the human sequence.

The sequences of rat and human Pal cDNAs have been deposited with the DNA data bank of Japan/European Molecular Biology Laboratory/GenBank nucleotide sequence databases under accession numbers AB028461 and AB031547, respectively.

\section{Expression of Pal mRNA in the retina}

To confirm Pal expression in the developing retina, RNA from P1, P7, P14, and P56 rat retina was analyzed by Northern blotting using rat Pal cDNA as a probe (Fig. $2 A$ ). No signals were found at P1. A single transcript of $4.3 \mathrm{~kb}$ was observed at P7, with the signal showing marked increases with subsequent development. In agreement with the findings of Northern blot analysis, in situ hybridization of developing rat eye sections demonstrated the same expression pattern (Fig. $2 B$ ); i.e., no positive signals were detected at P1 but the expression was found at P7 in the presumptive photoreceptor layer. Increased signal intensity was seen in the outer nuclear layer and the inner segment at P14 and P56. These observations indicated that Pal mRNA was specifically expressed in the photoreceptor cells.

To examine the tissue specificity of Pal expression, various adult rat tissue RNAs were analyzed by Northern blotting. Among the 10 different tissues analyzed, expression of Pal mRNA was observed only in the retina (Fig. $2 C$ ), indicating that $\mathrm{Pal}$ is a retina-specific gene.

\section{Cellular and subcellular distribution of $\mathrm{Pal}$ in the retina}

To examine the localization of $\mathrm{Pal}$ protein in rat retina, we generated a polyclonal antibody against the Pal peptide sequence (419-434). We performed immunoprecipitation and immunoblotting assays of membrane fractions of rat retina. Anti-Pal antibody reacted with a single band of $\sim 75 \mathrm{kDa}$ in the membrane fractions of the retina (Fig. $3 A$ ) and did not cross-react with other molecules containing the FN III domain. In contrast, immunoblotting of brain membrane fractions showed no Pal immunoreactivities. Thus, we confirmed that Pal was specifically expressed in the retina and that this antibody could successfully detect the endogenous Pal protein.

The distribution of $\mathrm{Pal}$ protein in the retina was examined immunohistochemically. No immunoreactive cells were observed in retina at $\mathrm{P} 1$, but the presumptive photoreceptor outer segments showed weak Pal immunoreactivity at P7 (Fig. 3B). At P14 and P56, anti-Pal antibody intensely labeled the outer segments of the photoreceptor cells, showing that Pal protein is localized and functions in the outer segments of the photoreceptor cells. Pre- 
Figure 3. Cellular localization of $\mathrm{Pal}$ protein. $A$, The membrane fraction of rat brain $(b)$ and retina $(r)$ immunoprecipitated and blotted with anti-Pal polyclonal antibody. $B, C$, Immunohistochemical analysis of the rat retina with anti-Pal antibody. $B$, A cryostat section of the retina was incubated with preimmune serum or anti-Pal antibody. Pal immunoreactivities are observed specifically in the outer segment (arrowhead). Note that the reaction in GCL is nonspecific because preimmune serum reacts to the same region. $G C L$, Ganglion cell layer; $I P L$, inner plexiform layer; $I N L$, inner nuclear layer; $O N L$, outer nuclear layer; $I S$, inner segment; $O S$, outer segment. Scale bar, $50 \mu \mathrm{m}$. $C$, Immunofluorescent labeling in each developing stage of the rat retina. No immunoreactive cells were observed at P1. Positive signals were observed in the presumptive photoreceptor outer segments at P7. Intense immunoreactivities are shown in the outer segments of P14 and the adult retina (arrowhead). NBL, Neuroblastic layer. Scale bar, $50 \mu \mathrm{m}$.
A
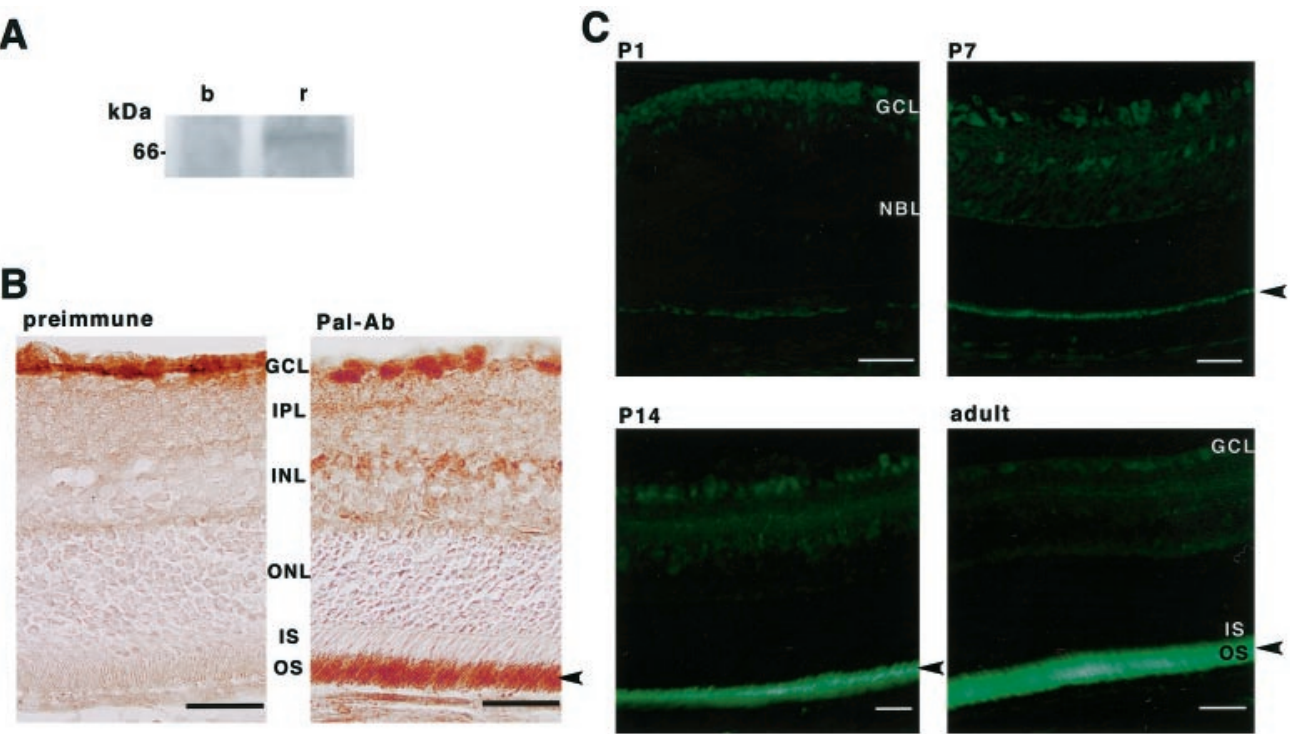

adult

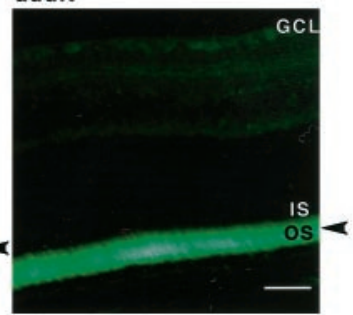

Figure 4. Subcellular localization of Pal protein. Electron micrographs of rod photoreceptors. LR White resin-embedded rod photoreceptor cells were labeled with the polyclonal antibody and immunogold particles. Labeling was found in the outer segment $(O S$, left $)$ but not in the inner segment (IS, middle). The particles were specifically localized on the disk membranes (right). Scale bar, $200 \mathrm{~nm}$.
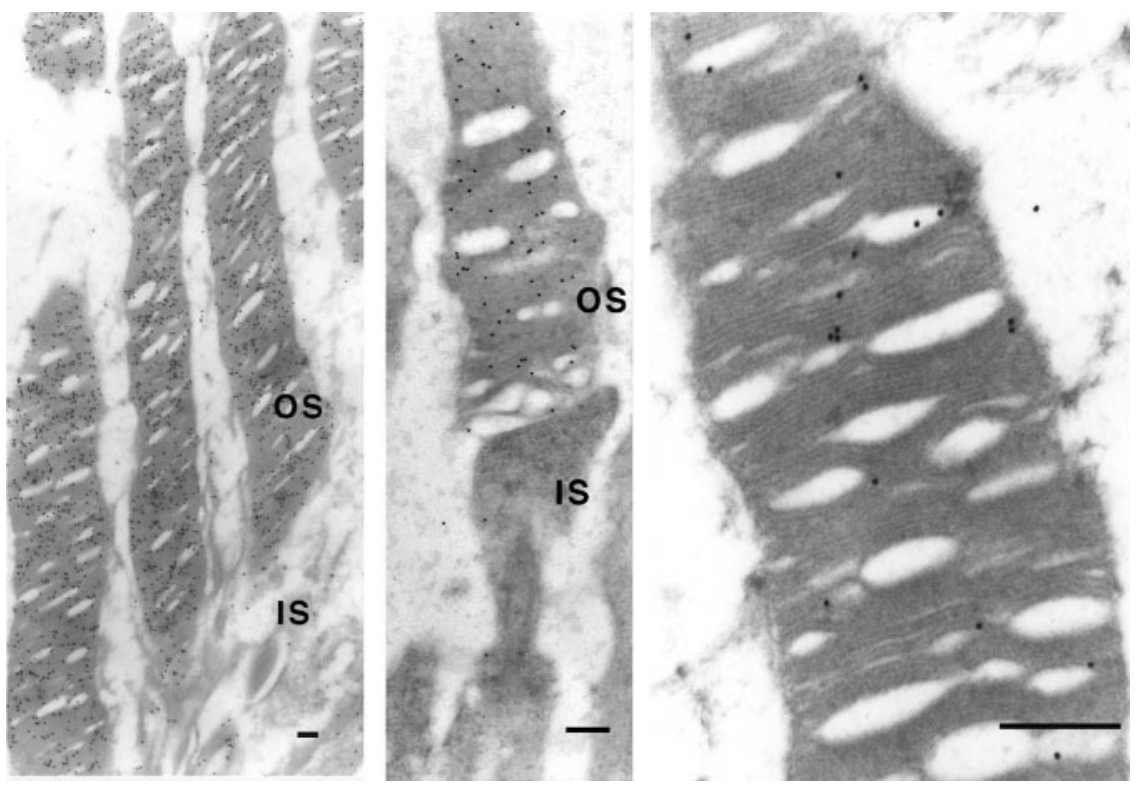

immune sera did not stain photoreceptor cells in this region (Fig. $3 C$ ). In addition, no immunoreactivity was seen when the antibody was preabsorbed with an excess amount of antigen (data not shown).

To demonstrate ultrastructural localization of $\mathrm{Pal}$ in photoreceptor cells, the immunogold labeling method for electron microscopy was used. LR White resin-embedded retinal sections were labeled with the polyclonal antibody for Pal, and immunogold particles were distributed diffusely on the disk membrane in the lamellar regions (Fig. 4).

\section{Molecular topology of Pal in mammalian cells}

Pal contains a signal sequence at its $\mathrm{N}$-terminal region. The molecular topology of Pal on the disk membrane was presumed to be that the N-terminal region was oriented toward the disk lumen. To confirm this, we examined the orientation of Pal on the membrane in HeLa cells that were transiently transfected with the expression plasmids for Pal tagged with the FLAG epitope.
Cells expressing Pal showed no morphological changes. Pal immunoreactivities were not observed on the plasma membrane under either permeabilized or nonpermeabilized conditions, suggesting that $\mathrm{Pal}$ is not translocated to the plasma membrane (Fig. 5). In contrast, when the cells were permeabilized by Triton $\mathrm{X}-100$, both anti-Pal antibody, which recognizes the N-terminal side of $\mathrm{Pal}$, and anti-flag antibody, which recognizes the $\mathrm{C}$-terminal side of Pal, detected $\mathrm{Pal}$ molecules at the perinuclear regions (Fig. 5). The double staining of Pal and GRP78, ER markers, showed that these proteins were colocalized in the ER. These data indicate that Pal is predominantly localized on the ER. We also examined Pal immunoreactivities under conditions that just permeabilized the plasma membrane, using saponin as the detergent (Fig. 5) (Radhakrishna and Donaldson, 1997). Anti-flag antibody detected the Pal molecules. In contrast, antiPal antibody failed to detect the Pal molecules, indicating that the $\mathrm{N}$-terminal portion of $\mathrm{Pal}$ is oriented toward the lumen of the ER 
$(-)$
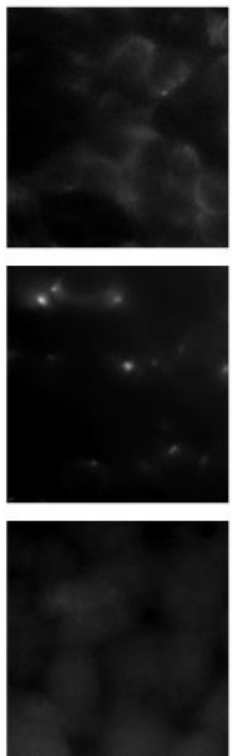

saponin
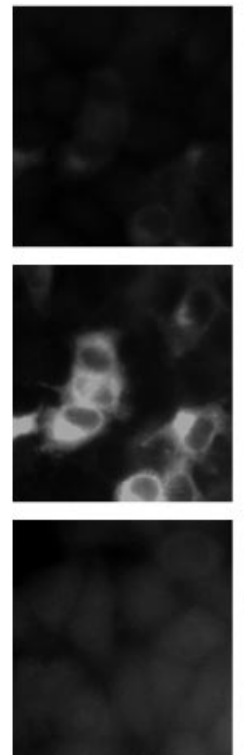
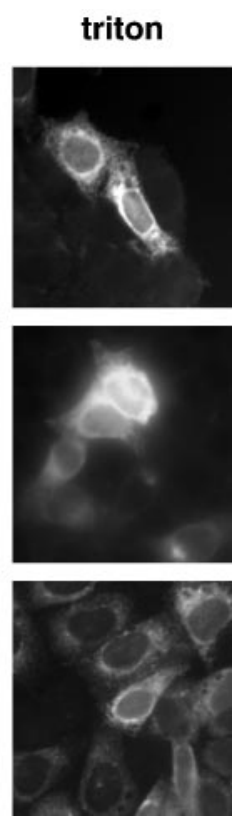

Figure 5. Molecular topology of Pal in HeLa cells. HeLa cells were transiently transfected with the expression plasmid of Pal tagged with the FLAG epitope at the $\mathrm{C}$ terminus. Immunocytochemistry was performed using each antibody (indicated at left) under the indicated permeabilized conditions. Saponin permeabilizes only the plasma membrane because immunoreactivities of GRP78, which is resident within the ER, are not observed. Under the condition permeabilized by saponin, anti-Pal antibody failed to detect immunoreactivities of Pal. In contrast, anti-FLAG antibody detected the Pal molecule in the ER, indicating that the $\mathrm{C}$-terminal region of $\mathrm{Pal}$ is oriented toward cytoplasm.

and the C-terminal portion is oriented toward cytoplasm. From the membrane architecture of the outer segment, it was considered that the molecular topology of the transmembrane proteins were identical at the ER and the disk of photoreceptor cells. Taken together, this suggested that the N-terminal portion of the Pal molecule could be oriented toward the interior of the disks.

\section{Biochemical characteristics of Pal protein}

Pal is considered to be capable of binding to itself or to other adhesion molecules because it contains a C2-type Ig-like domain and an FN domain. We examined the homodimerization activity of Pal by transient transfection.

The expression plasmids for Pal tagged with the FLAG epitope were transfected into $293 \mathrm{~T}$ cells. Western blotting with antiFLAG antibody showed a band of $75 \mathrm{kDa}$ and a minor $150 \mathrm{kDa}$ band (Fig. $6 A$ ). This pattern of bands on SDS-PAGE suggested that Pal formed a homodimer. To confirm this, an expression plasmid was also prepared producing HA-tagged Pal and cotransfected into 293 T cells with the FLAG-tagged Pal plasmid. Immunoprecipitation was performed using anti-FLAG monoclonal antibody followed by immunoblotting with anti-HA antibody. For the reverse experiment, we performed immunoprecipitation using anti-HA antibody, followed by blotting with anti-FLAG antibody. Both types of Western blotting showed that 75 and 150 kDa components were coimmunoprecipitated with FLAG- and HA-tagged Pal (Fig. 6B). These findings confirmed that Pal showed a strong homodimer structure that is resistant to SDS and boiling.

\section{Chromosomal mapping}

The initial fluorescence in situ hybridization (FISH) experiment resulted in specific labeling of the long arm of chromosome 10. A

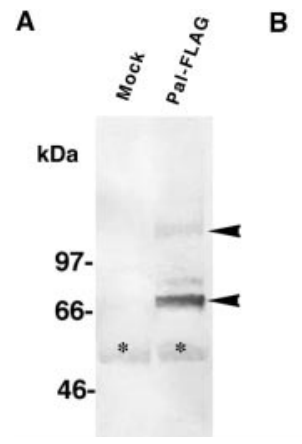

B

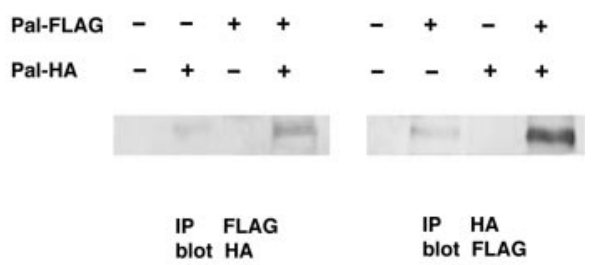

Figure 6. Homodimerization of Pal protein. A, Western blotting of Pal protein tagged with the FLAG epitope sequence. Aliquots of $10 \mu \mathrm{g}$ of plasmids of Pal tagged with the FLAG epitope (Pal-FLAG) or empty vector (Mock) were transiently transfected into HEK293T cells (right). Western blotting with anti-FLAG antibody showed both a major $75 \mathrm{kDa}$ band and a minor $150 \mathrm{kDa}$ band (arrowheads). Asterisk indicates nonspecific signals. $B$, Immunoprecipitation followed by Western blotting. A Pal expression plasmid tagged with the HA epitope (Pal-HA) was also constructed. 293T cells were transiently transfected with the indicated plasmids. Transfection was performed with equal amounts of plasmid DNA using empty plasmid as a control. Left, Lysates were immunoprecipitated $(I P)$ with anti-FLAG antibody and blotted with anti-HA antibody. Right, Immunoprecipitates with anti-HA antibody were immunoblotted with anti-FLAG antibody. Intense $75 \mathrm{kDa}$ bands were seen in the cotransfection lane.

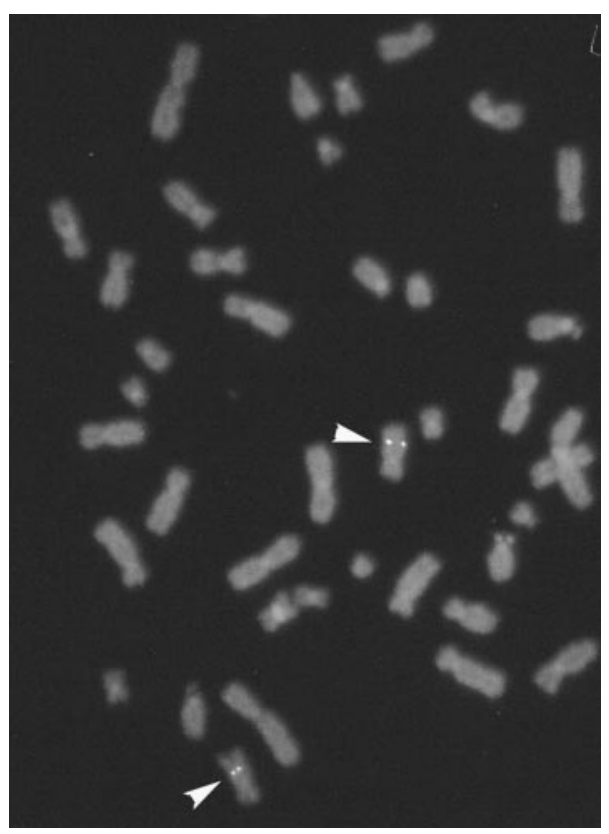

Figure 7. Chromosomal mapping of the human Pal gene by FISH. Specific hybridization signals were detected on human chromosome 10q23-q24. A total of 80 metaphase cells were analyzed, with 70 exhibiting specific labeling.

second experiment was conducted in which a probe, which had previously been mapped to 10q25, was cohybridized with Pal. Measurements of specifically labeled chromosome 10 demonstrated that Pal was located at a position that was $49 \%$ of the distance from the centromere to the telomere of chromosome arm 10q, an area that corresponds to 10q23.2-23.3 (Fig. 7). A total of 80 metaphase cells were analyzed, with 70 exhibiting specific labeling. 


\section{DISCUSSION}

We have isolated a novel retina-specific gene, Pal. Primary structure analysis indicated that the Pal protein contains unique functional domains such as LRRs, Ig C2, and FN III. LRR is a repetitive motif made up of several copies of amino acid residues with the conserved sequence LxxLxxLxLxxNxLxxLxxxxFxx. This motif is thought to be involved in highly specific proteinprotein interactions or cell adhesion (for review, see Kobe and Deisenhofer, 1994). The Ig C2 and FN III domains have also been implicated in adhesion or binding to other proteins (for review, see Williams and Barclay, 1988; Holness and Simmons, 1994). These motifs can be adapted to specific functions by variation and repetition and by combination with other motifs. Members containing both LRR and the Ig C2 domain have only been cloned from a few genes such as Trk receptors [trkA (Martin-Zanca et al., 1989); trkB (Klein et al., 1989); trkC (Lamballe et al., 1991)], LIG-1 (Suzuki et al., 1996), ISLR (Nagasawa et al., 1997), and Drosophila kek1/2 (Musacchio and Perrimon, 1996). Most of these proteins play significant roles in differentiation and development of tissues such as the CNS. However, other than in Trk receptors, the mechanisms by which these genes are involved in such phenomena have not been determined. Trk receptors are transmembrane glycoproteins containing LRR, Ig $\mathrm{C} 2$, and a cytosolic tyrosine kinase domain (Schneider and Schweiger, 1991). Neurotrophins selectively bind to Trk receptors and transduce signaling through phosphorylation by their tyrosine kinase domain (Kaplan and Stephens, 1994). The LRR and Ig-like domain of Trk receptors have been indicated as being important for specific ligand binding (Pérez et al., 1995; Urfer et al., 1995; Windisch et al., 1995). It has also been shown that Trk receptors function as homodimers (Jing et al., 1992, Schlessinger and Ullrich, 1992). Although Pal lacks the tyrosine kinase domain, its domain organization is similar to that of Trks. In addition, Pal molecules expressed in mammalian cells revealed dimerization similar to Trks. Therefore, it is possible that Pal may act as a receptor for a certain trophic factor.

The cells expressing Pal were photoreceptor cells in the retina. In the development of the retina, Pal expression begins at P7 and increases with developmental stage; i.e., the expression of Pal corresponds to the fact that photoreceptor cells respond to light and perform phototransduction. Thus, it is likely that Pal might take part in phototransduction, or be indirectly associated with the phototransduction system through morphogenesis or maintenance of photoreceptors.

Ultrastructually, the protein encoded by the Pal gene was distributed in the lamellar region of the disk in photoreceptor cells, a region in which rhodopsin captures a photon and initiates the phototransduction. The N-terminal region of Pal containing LRRs, Ig C2, and FN III is presumed to be oriented toward the intradiskal space from the results of overexpression of $\mathrm{Pal}$ in HeLa cells. Several possible roles are suggested from its structure and localization. First, Pal may bind to some molecules in the intradiskal space and transduce the signals to cytoplasm like a receptor for trophic factors. Second, Pal may interact with other disk membrane proteins such as rhodopsin at its intradiskal domain. Rhodopsin is distributed diff usely and abundantly on the lamellar region of disks. The contact to disk membrane proteins may contribute to maintain the membrane structure of disks. Another possibility is that Pal might play a role as an adhesion molecule. NCAM is representative of such an adhesion molecule containing both Ig C2 and FN III domains. NCAM also shows homophilic interaction and is considered to stimulate neuronal outgrowth and differentiation by activating some signaling pathways (Walsh and Doherty, 1997). Therefore, Pal also may mediate signals through homophilic binding. However, we cannot exclude other functions of Pal on photoreceptor disks. Further studies are required to determine the precise roles of Pal on the disk membrane. To clarify the roles of this molecule, the generation of Pal-deficient mice is currently being undertaken.

Mutations in approximately 20 genes have been found to cause forms of nonsyndromic RP (for review, see van Soest et al., 1999). A recent update of all genes involved in retinal diseases can be found through RetNet (http://www.sph.uth.tmc.edu/RetNet/). Because almost half of the identified RP genes encode photoreceptor-specific proteins, the human homolog of Pal is a potential candidate disease gene for inherited retinal degenerations. The Pal gene was mapped to chromosome 10q23.2-23.3 by FISH. Although no RP genes have been mapped to this chromosomal location, it is believed that other genes may be involved in RP. In addition, genes involved in Usher syndrome types $1 \mathrm{f}$ and $1 \mathrm{~d}$ are known to be localized to 10 and $10 \mathrm{q}$, respectively (Wayne et al., 1996, 1997). Usher syndrome is an autosomal recessive disorder, and affected individuals develop sensorineural hearing deficiencies and progressive RP. Because we did not examine the expression of Pal in auditory systems, it is not known whether mutations in Pal cause damage to these systems. Further investigations are needed to elucidate whether mutations in the Pal gene are linked to Usher syndrome or other diseases.

\section{REFERENCES}

Ahmad I, Redmond LJ, Barnstable CJ (1990) Developmental and tissue-specific expression of the rod photoreceptor cGMP-gated ion channel gene. Biochem Biophys Res Commun 173:463-470.

Bascom RA, Manara S, Collins L, Molday RS, Kalnins VI, McInnes RR (1992) Molecular cloning of the cDNA for a novel photoreceptorspecific membrane protein (rom-1) identifies a disk rim protein family implicated in human degenerative retinopathies. Neuron 8:1171-1184.

Cepko CL, Austin CP, Yang X, Alexiades M, Ezzeddine D (1996) Cell fate determination in the vertebrate retina. Proc Natl Acad Sci USA 93:589-595.

Connell G, Molday RS (1990) Molecular cloning, primary structure, and orientation of the vertebrate photoreceptor cell protein peripherin in the rod outer segment disk membrane. Biochemistry 29:4691-4698.

Cook NJ, Hanke W, Kaupp UB (1987) Identification, purification and functional reconstitution of the cyclic GMP-dependent channel from rod photoreceptors. Proc Natl Acad Sci USA 84:585-589.

Dryja TP, McGee TL, Reichel E, Hahn LB, Cowley GS, Yandell DW, Sandberg MA, Berson EL (1990) A point mutation of the rhodopsin gene in one form of retinitis pigmentosa. Nature 343:364-366.

Grun G (1982) The development of the vertebrate retina: a comparative survey. Adv Anat Embryol Cell Biol 78:1-83.

Hicks D, Barnstable C (1987) Different rhodopsin monoclonal antibodies reveal different binding patterns on developing adult rat retina. J Histochem Cytochem 35:1317-1328.

Holness CL, Simmons DL (1994) Structural motifs for recognition and adhesion in members of the immunoglobulin superfamily. J Cell Sci 107:2065-2070

Imaizumi K, Tsuda M, Wanaka A, Tohyama M, Takagi T (1994) Differential expression of sgk mRNA, a member of the Ser/Thr protein gene family, in rat brain after CNS injury. Mol Brain Res 26:189-196.

Jing S, Tapley P, Barbacid M (1992) Nerve growth factor mediates signal transduction through trk homodimer receptors. Neuron 9:1067-1079.

Kajiwara K, Hahn LB, Mukai S, Travis GH, Berson EL, Dryja TP (1991) Mutations in the human retinal degeneration slow gene in autosomal dominant retinitis pigmentosa. Nature 354:480-483.

Kaplan DR, Stephens RM (1994) Neurotrophin signal-transduction by the trk receptor. J Neurobiol 25:1404-1417.

Klein R, Parada LF, Coulier F, Barbacid M (1989) trk B, a novel 
tyrosine protein kinase receptor expressed during mouse neural development. EMBO J 8:3701-3709.

Kobe B, Deisenhofer J (1994) The leucine-rich repeat: a versatile binding motif. Trends Biochem Sci 19:415-421.

Körschen HG, Illing M, Seifert R, Sesti F, Williams A, Gotzes S, Colville C, Müller F, Dosé A, Godde M, Molday L, Kaupp UB, Molday RS (1995) A $240 \mathrm{kDa}$ protein represents the complete subunit of the cyclic nucleotide-gated channel from rod photoreceptor. Neuron 15:627-636.

Lamballe F, Klein R, Barbacid M (1991) trk C, a new member of trk family of tyrosine protein kinases, is a receptor for neurotrophin-3. Cell 66:967-979.

Lochrie MA, Hurley JB, Simon MI (1985) Sequence of the alpha subunit of photoreceptor $\mathrm{G}$ protein: homologies between transducin, ras, and elongation factors. Science 228:96-99.

Martin-Zanca D, Oskma R, Mitra G, Copeland T, Barbacid M (1989) Molecular and biochemical characterization of the human trk protooncogene. Mol Cell Biol 9:24-33.

Musacchio M, Perrimon N (1996) The Drosophila kekkon gene: novel members of both the leucine-rich repeat and immunoglobulin superfamilies expressed in the CNS. Dev Biol 178:63-76.

Nagasawa A, Kubota R, Imamura Y, Nagamine K, Wang Y, Asakawa S, Kudoh J, Minoshima S, Mashima Y, Oguchi Y, Shimizu N (1997) Cloning of the cDNA for a new member of the immunoglobulin superfamily (ISLR) containing leucine-rich repeat. Genomics 44:273-279.

Nathans J, Hogness DS (1984) Isolation and nucleotide sequence of the gene encoding human rhodopsin. Proc Natl Acad Sci USA 81:4851-4855.

Ni M, Yamaki K, Kikuchi T, Ferrick M, Shinohara T, Nussenblatt R, Chan CC (1992) Developmental expression of S-antigen in fetal human and rat eye. Curr Eye Res 11:219-229.

Pérez P, Coll PM, Hempstead BL, Martín-Zanca D, Chao MV (1995) NGF binding to the trk tyrosine kinase receptor requires the extracellular immunoglobulin-like domain. Mol Cell Neurosci 6:97-105.

Radhakrishna H, Donaldson JG (1997) ADP-ribosylation factor 6 regulates a novel plasma membrane recycling pathway. J Cell Biol 139:49-61.

Reh TA (1992) Generation of neuronal diversity in the vertebrate retina.
In: Determinants of neuronal identity (Shankland M, Macagno ER, eds), pp 433-467. New York: Academic.

Schlessinger J, Ullrich A (1992) Growth factor signaling by receptor tyrosine kinases. Neuron 9:383-391.

Schneider R, Schweiger M (1991) A novel modular mosaic of cell adhesion motifs in the extracellular domains of the neurogenic trk and trkB tyrosine kinase receptors. Oncogene 6:1807-1811.

Small SJ, Shull GE, Santoni MJ, Akeson R (1987) Identification of a cDNA clone that contains the complete coding sequence for a $140-\mathrm{kD}$ rat NCAM polypeptide. J Cell Biol 105:2335-2345.

Suzuki Y, Sato N, Tohyama M, Wanaka A, Takagi T (1996) cDNA cloning of a novel membrane glycoprotein that is expressed specifically in glial cells in the mouse brain. J Biol Chem 271:22522-22527.

Urfer R, Tsoulfas P, O'Connell L, Shelton DL, Parada LF, Presta LG (1995) An immunoglobulin-like domain determines the specificity of neurotrophin receptors. EMBO J 14:2795-2805.

van Soest S, Westerveld A, De Jong PTVM, Bleeker-Wagemakers EM, Bergen AAB (1999) Retinitis pigmentosa: defined from a molecular point of view. Surv Ophthalmol 43:321-334.

Walsh FS, Doherty P (1997) Neural cell adhesion molecules of the immunoglobulin superfamily: role in axon growth and guidance. Annu Rev Cell Dev Biol 13:425-456.

Wayne S, Der Kaloustian VM, Schloss M, Polomeno R, Scott DA, Hejtmancik JF, Sheffield VC, Smith RJ (1996) Localization of the Usher syndrome type 1D gene (USH1D) to chromosome 10. Hum Mol Genet 10:1689-1692.

Wayne S, Lowry RB, McLeod DR, Knaus R, Farr C, Smith RJ (1997) Localization of the Usher syndrome type $1 \mathrm{~F}(\mathrm{Ush} 1 \mathrm{~F})$ to chromosome 10. Am J Hum Genet 61:A300.

Williams AF, Barclay AN (1988) The immnoglobulin superfamily: domains for cell surface recognition. Annu Rev Immunol 6:381-405.

Windisch JM, Marksteiner R, Lang ME, Auer B, Schneider R (1995) Brain-derived neurotrophic factor, neurotrophin-3, and neurotrophin-4 bind to a single leucine-rich motif of TrkB. Biochemistry 34:1125611263. 